\title{
PRONE TO BIAS: TOWARDS A THEORY OF INDIVIDUAL DIFFERENCES IN BIAS MANIFESTATION
}

\author{
SHAUL OREG \\ Department of Sociology and Anthropology \\ University of Haifa, Mt. Carmel 31905, Israel \\ MAHMUT BAYAZIT \\ Koc University, Turkey
}

\section{INTRODUCTION}

\begin{abstract}
A bias can be defined as an erroneous response that constitutes a departure from normative standards (e.g., Evans \& Over, 1996). In the vast majority of studies that document biases, the biased response is considered ubiquitous, and individual differences in bias manifestations are treated as noise or error. Accumulating evidence suggests, however, that a substantial amount of systematic variability in individuals' judgments and choices is not accounted for and could be explained by considering stable individual differences (e.g., Budescu, Wallsten, \& Au, 1997). Individuals' judgments and preferences have been found highly consistent across domains. Depending on their dispositions, individuals can be classified as more or less prone to exhibit different kinds of biases. Indeed, several studies have demonstrated relationships between dispositional variables, such as self-esteem or the need for cognitive closure and bias phenomena such as escalation of commitment or the self-serving bias (e.g., Stanovich \& West, 1998c; Whyte, Saks, \& Hook, 1997). However, such works have been sporadic and have lacked an overarching theory that incorporates the broad spectrum of biases that have been studied in a variety of domains.

In this paper we propose that biases predominantly arise in the process of striving for basic motivational goals and that people's dispositions determine the extent to which these biases occur. By considering three fundamental motivational goals, or desired end-states, our theory offers a categorization of the many biases that have been discussed over the years. We suggest that the majority of biases can be categorized into one of three categories: Verification, regulation, or simplification biases. We discuss here the first two categories. ${ }^{1}$
\end{abstract}

\section{END-STATES, INDIVIDUAL DIFFERENCES, AND BIAS}

We argue that, by and large, each of the biases discussed in the literature can be categorized into one of three types. Each type involves a distortion that occurs in the process of trying to satisfy one of three motivational end-states: Some biases involve distortions in people's perceptions of themselves and of the world. We term these verification biases and argue that they occur in the course of trying to achieve coherence. Other biases involve non-normative choices and behaviors, which we term regulation biases. These occur when trying to approach pleasure and to avoid pain. A third category involves cognitive distortions and inaccuracies in the way people process information and analyze problems. These simplification biases will occur in the process of trying to comprehend reality. Although individuals generally strive to achieve these basic end-states (coherence, pleasure without pain and a comprehensible reality), differences in the way people typically approach them will result in bias variations. 


\section{Achieving coherence: Biases in perceptions of the self and of the world}

Numerous psychologists have pointed out people's basic need to achieve consistency in their cognitions (for a review see Abelson et al., 1968). Some explanations of this need rely on the premise that inconsistency, or dissonance, between cognitions involves unpleasant tension that individuals try to eliminate by achieving consistency (e.g., Festinger, 1957). Other explanations of the search for consistency, in particular in regards to the self, suggest that people seek consistency because it provides them with a sense of predictability and control (Swann \& Read, 1981) and a sense of coherence (Swann, Rentfrow, \& Guinn, 2002).

To acheive coherence, people adopt a variety of strategies (Swann, Griffin, Predmore, \& Gaines, 1987). Among these are cognitive strategies in which people distort reality by paying closer attention to information that confirms their self-view; by preferring self-view-confirming interpretations of new information; and by tending to better remember such confirming interpretations. According to Swann et al., (2002), the motivation to self-verify is so strong that people will even prefer to maintain negative self-views than to adopt an incongruent positive view of the self (e.g., Lecky, 1951; Swann et al., 1992). While we agree that the search for coherence is a universal basic motivation, we suggest that the dispositional lenses with which people strive for coherence will determine the extent to which their self-verifying strategies will entail accurate versus biased perceptions. More specifically we argue that individuals' core evaluations will moderate the manifestation of, what we call, verification biases.

The impact of core self evaluations on the manifestation of verification biases. Core evaluations are fundamental implicit beliefs that people hold, which influence all of their appraisals (Judge, Locke, \& Durham, 1997). Particular attention has been devoted to core selfevaluations, which are represented in four personality traits: self-esteem, generalized selfefficacy, neuroticism, and locus of control, all of which involve how individuals perceive themselves.

In their search for coherence, people seek to confirm their core evaluations in the day-today events that they encounter. Because events do not always conform to people's beliefs about themselves and about reality, coherence can only be achieved if non-conforming evidence is somehow distorted to meet with extant beliefs (i.e., core evaluations). Because these distortions come about in the course of trying to verify ones beliefs, we call biases that result from such distortions, verification biases.

Verification biases involve distortions in people's perceptions of self and reality and, as we will argue, include biases such as, self-serving bias, overconfidence, false-consensus, illusions of control, and unrealistic optimism. These biases have generally been considered inevitable human tendencies that involve an egocentric and inflated positive image of the self and of reality. These inflated images have often been explained by suggesting that people are motivated to self-enhance. These biases have therefore been previously considered enhancement biases (e.g., Baumeister, 1998). We argue that individuals' core evaluations ultimately contribute to the existence and to the direction of such biases, and that, in many contexts, a self-verification rather than a self-enhancement explanation may better explain the nature of these biases.

All else being equal, stable individual differences in core evaluations will determine whether a bias in the interpretation of reality will occur and whether its direction will be to distort upwards (i.e. to hold an overly positive view) or downwards (i.e., to hold an overly negative view). Individuals with positive core self evaluations (e.g., high self-esteem) approach situations generally believing that they are able to cope with difficulties, that they are 
knowledgeable and right, and that their attributes lead to desirable rather than undesirable ends. These individuals are constantly in search for evidence that supports their positive evaluations and are therefore drawn to utilize, whether consciously or not, biases that enable them to verify and maintain their positive beliefs even in the face of negative information.

On the other hand, those with negative core evaluations seek consistency with their negative beliefs. Rather than apply upward distorting strategies that would enhance their selfimage, they accept failures as a verification of their self-beliefs. Furthermore, to achieve coherence they apply downward distorting strategies and downplay their achievements in the face of successes. These downward distortion yield self-depreciating biases such as underconfidence, unrealistic pessimism, and learned helplessness. The entire notion of seeking consistency depends on what it is that people try to be consistent with. Upward distortions (e.g., unrealistic optimism) will prevail where core evaluations are positive, and downward distortions (e.g., unrealistic pessimism) will prevail where core evaluations are negative.

Several studies, that found ties between personality traits and the manifestation of specific biases, support such an argument. For example, high self-esteem individuals have been found to be more likely to use self-serving attributions (Miller et al., 1975), more likely to compensate for losses incurred after negative feedback (e.g., Wood, Giordano Beech, Taylor, \& Michela, 1994), more likely to overestimate consensus for their opinions and underestimate consensus for their perceived abilities (Campbell, 1986), more likely to derogate sources of negative feedback and compliment sources of positive feedback (Baumgardner et al., 1989), and have been found to show more overconfidence in their evaluations of their performance (Kramer, Newton, \& Pommerenke, 1993). Blaine and Crocker (1993) reviewed the cumulating, and often conflicting, works that have considered self-esteem and self-serving biases, and concluded that whereas high self-esteem individuals are more likely to exhibit self-serving biases, those with low self-esteems are more likely to either perceive reality even-handedly, or to self-depreciate.

Similarly, research on depression, which involves negative self evaluations, provides similar support to our claims. In one study, individuals suffering from major depression were significantly less confident in their correct responses in comparison to non-depressed subjects (Hancock, Moffoot, \& O'Carroll, 1996). In an extensive review of the "depressive realism" phenomenon, Ruehlman et al. (1985) conclude that whereas non-depressed individuals manifest positivistic evaluative responses, severely depressed individuals manifest negativistic evaluative biases. On the other hand, "mildly depressed persons tend to display unbiased (neither positivistic nor negativistic) evaluative response patterns" (p. 46). We therefore hypothesize: Proposition 1a: Individuals with positive core evaluations of the self are more likely to exhibit upward-distorting verification biases such as the self-serving bias, overconfidence, unrealistic optimism, illusions of control and false consensus. Proposition 1b: Individuals with negative core evaluations of the self are more likely to exhibit downward-distorting verification biases such as self-diminishment, underconfidence, unrealistic pessimism, learned helplessness and false uniqueness.

\section{Approaching pleasure and avoiding pain: Biases in people's choices and behaviors}

The most basic of human motivations are to approach pleasure and to avoid pain (e.g., Freud, 1950). However, there may be different means of approaching pleasure and avoiding pain. According to Higgins' (1997) theory of regulatory focus, pleasure and pain can be derived 
from either positive or negative outcomes. A promotion regulatory focus involves a focus on rewards, such that pleasure and pain are a result of either gaining or failing to gain positive outcomes. On the other hand under a prevention focus, pleasure and pain stem from failing or succeeding to avoid negative outcomes. Furthermore, a promotion focus indicates a long-term perspective, increased sensitivity to intrinsic needs, and a concern with reaching one's aspirations, whereas a prevention focus signifies a short-term perspective taking, sensitivity to social norms and pressures, and a concern for stability and protection (Higgins, 1998).

Regulatory foci have been shown to have implications for the decisions individuals make. Because individuals under a promotion orientation focus on positive outcomes, they are more sensitive to the presence or absence of positive outcomes (i.e., rewards) and attempt to ensure hits (i.e., successfully obtaining a positive outcome) and to avoid errors of omission (i.e., failing to obtain a potential positive outcome). On the other hand, individuals under a prevention focus are much more sensitive to the presence or absence of negative outcomes (i.e., punishments) and attempt to ensure correct rejections (i.e., successfully avoiding a negative outcome) and to avoid errors of commission (i.e., failing to avoid a negative outcome) (e.g., Crowe \& Higgins, 1997).

Regulatory focus is determined both by situational circumstances and individuals' chronic inclinations (Higgins, 1998). The existence of a chronic component means that although all people strive to approach pleasure and to avoid pain, there are individual differences in the means of achieving this. Some people chronically focus on positive outcomes, whereas others focus on negative ones. Therefore, individuals with a chronic promotion regulatory orientation are generally more likely to focus on opportunities for self-enhancement and growth, whereas those with a chronic prevention orientation will tend to focus on attaining stability and security.

\section{The impact of chronic regulatory foci on the manifestation of regulation biases.}

Regulation biases involve deviations from normative decision making and include biases such as framing bias, the endowment effect, the category response bias, escalation of commitment, and regret avoidance. All of these involve a bias in the choices and decisions that people make. Like most biases, regulation biases too have been considered inevitable, universal human tendencies (Kahneman \& Tversky, 1979). We argue that individuals' chronic regulatory focus ultimately contributes to the existence and the direction of such biases. Two of these biases are reviewed next.

The framing effect involves people's tendency to give more weight to potential losses than to potential gains (Kahneman \& Tversky, 1979). The displeasure associated with loss is greater than the pleasure that is associated with an equivalent gain. Therefore, when situations are framed in terms of gains, people tend to prefer definite small gains to uncertain larger gains (i.e., risk averse). On the other hand, when situations are framed in terms of losses, people tend to prefer uncertain great losses over certain smaller losses (i.e., risk-seeking). This effect matches Higgins (1998) conceptualization of prevention-focused behavior. Because individuals in a prevention mode focus on avoiding losses, they prefer the risk of a large loss over the certainty of a small one because the uncertain large loss still offers the chance of avoiding losses altogether. On the other hand, when offered the choice between a definite small gain, and an uncertain larger gain, prevention individuals are likely to be risk-averse and to prefer certainty because the definite gain does not entails any potential losses, whereas the uncertain gain does (i.e., the chance of remaining empty handed). In other words, chronic prevention individuals are likely to be risk seeking when the situation holds a loss frame, and risk averse when the situation holds a gain frame. Thus, framing bias is expected for people with a chronic prevention focus. 
Promotion oriented individuals, on the other hand, are expected to exhibit an opposite bias. In one study, individuals with a focus on prevention, but not promotion, tended to be risk seeking when making choices under a loss frame and risk averse when making choices under a gain frame (Josephs et al., 1992). Because of promotion individuals' focus on maximizing gain opportunities and on avoiding errors of omission, a gain frame would lead to risky choices whereby they would prefer an uncertain large gain, over a certain smaller one. On the other hand, because they are not focused on losses, they should prefer a definite small loss, over an indefinite greater one. Initial support for this argument can be found in one study in which promotion individuals were more likely to be risk seeking in a gain frame, but more likely to be risk averse in the loss frame (Kluger, Yaniv, \& Kuhberger, 2001). Therefore, both promotion and prevention foci may lead to risky choices. However, the two foci differ in the outcomes for which risks are taken. Prevention people make risky choices when they believe it is the only way to avoid losses and maintain their security, and will therefore exhibit the framing bias. On the other hand, promotion individuals make risky choices when they believe it will enable them to gain rewards and to approach their aspirations and will therefore exhibit a reversed-framing bias.

A similar pattern is evidenced in the endowment effect (Thaler, 1980), according to which once something is owned, its value increases. The bias is manifested when, after purchasing an item, many people expect to receive an amount higher than they paid for, to give the item up. This leads individuals to prefer a currently owned item over a different item of equal value. Consistent with our arguments above, studies have shown that whereas the endowment effect is observed for prevention orientated individuals, it is generally not exhibited among those with a chronic promotion focus (e.g., Liberman, Idson, Camacho, \& Higgins, 1999). Similar patterns of relationships with regulatory focus can also be demonstrated for biases such as the category boundary bias, escalation of commitment and regret avoidance (Oreg \& Bayazit, 2005). In sum, whereas regulation biases have generally been treated as universal, we argue that they are, at least to some extent, contingent on people's chronic regulatory focus:

Proposition 2a: Individuals who are high in their chronic prevention regulatory focus would be more likely to exhibit biases such as the framing bias, the endowment effect, overweighting of low and high probabilities, persistent escalation of commitment, and avoidance of regrets due to actions that stray from the status quo.

Proposition 2b: Individuals who are high in their chronic promotion regulatory focus would be more likely to exhibit biases such as the reversed framing and endowment effects, overweighting of mid-range probabilities, short-term escalation, and avoidance of regrets due to inaction.

\section{IMPLICATIONS FOR MANAGERIAL COGNITION AND PRACTICE}

Theory and research on managerial cognition and strategic management have been influenced substantially by the literature on cognitive biases (e.g., Barnes, 1984). Many of the biases discussed here, such as self serving causal attributions (e.g., Wagner \& Gooding, 1997), and framing (Bateman \& Zeithaml, 1989) have often been discussed in the strategic management context. Managers are not different from others in that they too are motivated to be consistent in their sense of self and to attain value by approaching pleasure and avoiding pain.

From the literature on leadership and management we know that overall, managers are likely to hold high positive self-evaluations (e.g., Bass \& Stogdill, 1990). This suggests that they 
would be particularly prone to exhibit biases such as overconfidence and to make self-serving attributions. It should not be surprising, therefore, to find managers who are certain of the brilliance of their organizational vision, who overestimate their chances of succeeding in new business ventures, and who push for deals that appear too good to be true.

Organizations risk becoming unresponsive to outside developments and becoming unable to learn from their mistakes when they are entrenched with excessive pride and perfectionism. This diminishes the organization's ability to reinterpret earlier situations in light of past events. If initial definitions cannot be undone, or redone, organizations risk losing their competitive advantage to those who are less confident and more willing to frequently reconsider their interpretation of events (Lant, Milliken, \& Batra, 1992). We believe that one of the reasons why such entrenched interpretations cannot be easily changed lies in the role of core self evaluations.

More important perhaps is the possibility that managers' dispositions and oft-related biases can provide meaning to other organizational members by selectively and automatically attending and interpreting strategic issues (Dutton \& Duncan, 1987). Contrary to normative prescriptions, different managers who are exposed to the same information often construct different interpretations of the same strategic issue (Fredrickson, 1985). Our theory provides an individual differences account by arguing that managers tend to label strategic issues in terms of either threats or opportunities and will therefore devise actions consistently as a function of their core-evaluations and chronic regulatory foci.

Finally, our theory suggests a link between cognitions and behavior. For example, the conservative behavioral responses (e.g., restriction in information processing and constriction in control) that follow interpretations of threat, called the threat-rigidity effect, have been previously explained through individuals' experience of stress, anxiety and physiological arousal (Staw, Sandelands, \& Dutton, 1981). We suggest that a chronic prevention orientation and its related biases (e.g. the endowment effect) may antecede threat-rigidity effects. To avoid pain (i.e., reduce perceived threats), prevention oriented managers may overemphasize the value of what they have or what they usually do (i.e., habituated responses) and will therefore search for solutions in the internal, rather than the external environment.

\section{CONCLUSIONS}

Numerous studies have been conducted with the aim of determining whether, and the extent to which, human perception and decision-making deviate from normative standards. It is by now well accepted that, at least to some extent, people bias. Nevertheless, extant findings lack an organizing framework that could explain how the different biases relate to one another. Furthermore, extant explanations lack the higher resolution that could more fully explain the psychological processes that underlie individuals' biased responses. We believe that an individual differences perspective is valuable for clarifying why and when people in general, and managers in particular, will bias.

\section{ENDNOTES}

1. Due to space limitations, several portions of our model could not be included here. For a discussion of our full model see Oreg \& Bayazit (2005).

\section{REFERENCES AVAILABLE FROM THE AUTHORS}


Copyright of Academy of Management Proceedings is the property of Academy of Management. The copyright in an individual article may be maintained by the author in certain cases. Content may not be copied or emailed to multiple sites or posted to a listserv without the copyright holder's express written permission. However, users may print, download, or email articles for individual use. 
Copyright of Academy of Management Proceedings is the property of Academy of Management and its content may not be copied or emailed to multiple sites or posted to a listserv without the copyright holder's express written permission. However, users may print, download, or email articles for individual use. 
Copyright of Academy of Management Annual Meeting Proceedings is the property of Academy of Management and its content may not be copied or emailed to multiple sites or posted to a listserv without the copyright holder's express written permission. However, users may print, download, or email articles for individual use. 